\section{'Roseberry' Strawberry}

\section{Shahrokh Khanizadeh ${ }^{\mathbf{1}}$, Martine Deschênes, and Claudine Dubé Agriculture and Agri-Food Canada, Horticulture Research and Development Centre, 430 Gouin Boulevard, St-Jean-sur-Richelieu, QC, Canada, J3B 3E6}

Additional index words. Fragaria ×ananassa, ornamental, pink-flowering, day-neutral, fruit breeding

'Roseberry' strawberry (Fragaria $\times a n$ anassa Duch.) is a day-neutral cultivar that produces attractive pink blooms and aromatic fruits all summer long. It has the added characteristics of producing flowers and fruits on stolons even before they root, which is very attractive in the garden. This cultivar is being released as an ornamental for home gardeners as a result of its pink-colored flowers and aromatic fruits. It was developed by the Agriculture and Agri-Food Canada (AAFC) strawberry breeding program located at the Horticulture Research and Development Center in St-Jean-sur-Richelieu, Quebec. The cultivar is suitable for hanging baskets and/or groundcover.

\section{Origin}

The original seedling resulted from pollinating SJ8518-11 (Raritan $\times$ K74-12) with pollen from SJ9616-1 $\times$ Pink Panda (Fig. 1). The cross was done in 1994 at our station in St-Jean-sur-Richelieu and the seedlings were planted in the field in 1995. 'Roseberry' was selected in 1996 by S. Khanizadeh and given the number SJO9625-86. Evaluation of this selection took place from 1997 to 2009 at the AAFC substation located in L'Acadie, $\approx 25$ $\mathrm{km}$ southeast of Montreal, Quebec.

\section{Description}

'Roseberry' plants are hardy and survived each winter during the test period with no damage when protected by $10 \mathrm{~cm}$ of straw cover. The pink-flowering cultivars Serenata and Viva Rosa used as controls often did not survive the winter conditions and usually had to be replanted each year. 'Roseberry' plants are very vigorous with a spreading habit. They produce multiple crowns and few (three) stolons in the first year of growth, but a medium (five) number of stolons are produced in the second and subsequent years, many (seven) for 'Rosalyne'. The stolons tend to produce flowers and fruits before rooting.

Received for publication 17 June 2010. Accepted for publication 20 July 2010.

Agriculture and Agri-Food Canada, St-Jean-surRichelieu, Contribution No. 335/2010.09.01R.

${ }^{1}$ To whom reprint requests should be addressed; e-mail Shahrokh.Kanizadeh@agr.gc.ca; www. khanizadeh.info.
The leaves are made up of three leaflets, the surface is medium green, and interveinal blistering is weak. Petioles are medium long with slightly outward hairs. The terminal leaflets are concave, much longer than broad with serrated to crenated margins and an obtuse base. The plants are less susceptible to
Fig. 1. Pedigree of 'Roseberry' strawberry.

Fig. 2. Flowers of 'Roseberry' (left) versus 'Rosalyne' (right).

Fig. 3. Fruits of 'Roseberry' (left) versus 'Rosalyne' (right). leaf spot [Mycosphaerella fragariae (Tul.) Lindau] and leaf scorch [Diplocarpon earliana (Ell. \& Ev.) Wolf] compared with 'Rosalyne' but this does not seem to weaken the plants or reduce their attractiveness.

Flower production starts in early July during the first year of growth and by midMay to early June the next and subsequent years. Flowering is continuous during the summer and lasts until the first frosts in fall. The inflorescences show many flowers and are placed at or above canopy. The flowers have five to seven petals, whereas normally five are typical of Fragaria (Hancock, 1999). They are large $(2.74 \mathrm{~cm}$ in diameter) compared with 'Rosalyne' $(2.12 \mathrm{~cm})$ with a corolla that is larger than the calyx (Fig. 2). The petals are overlapping and broader than long and mainly dark pink on the surface (Royal Horticultural Society, 1995), red-purple group
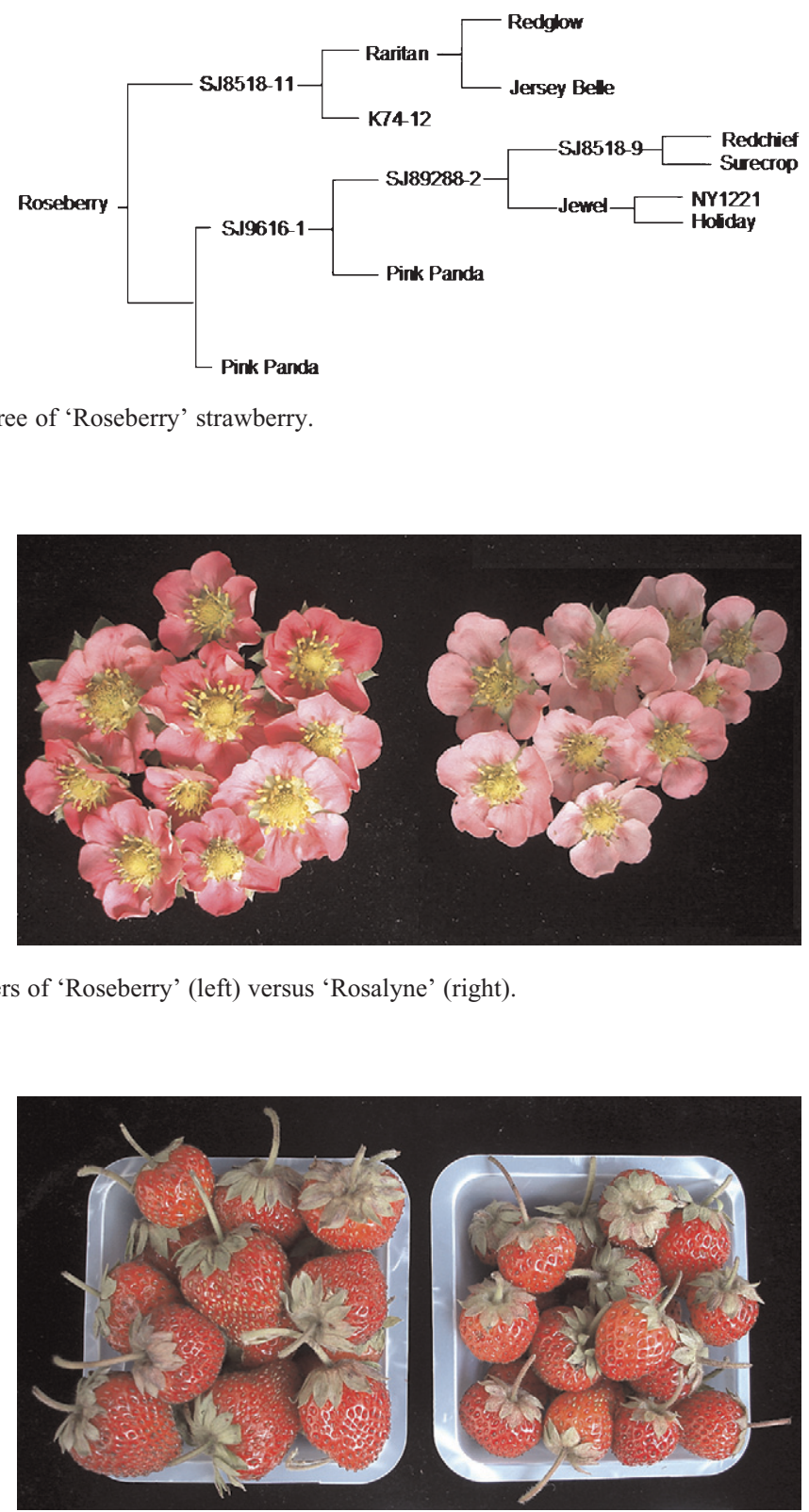

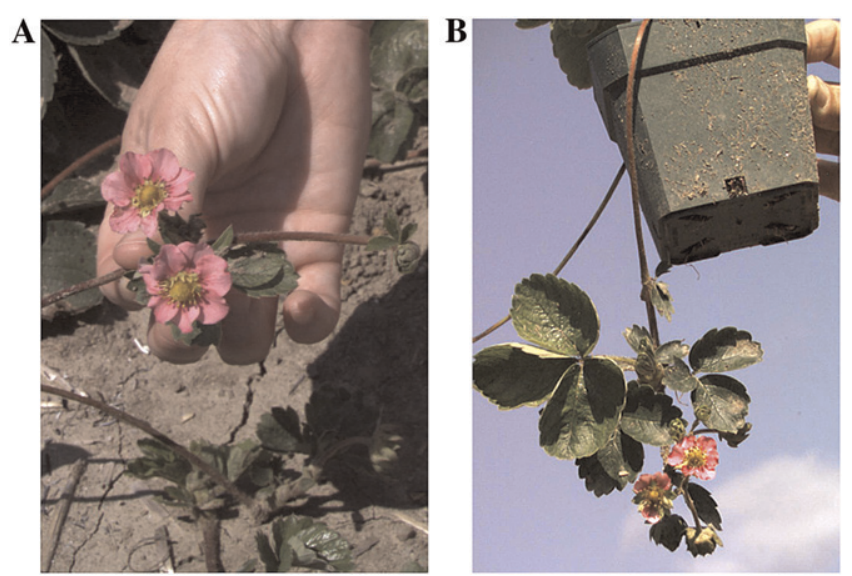

Fig. 4. Runners of the 'Roseberry' in the field and in the pot during multiplication.

67C, compared with those of 'Rosalyne', group $67 \mathrm{D}$.

The fruits start ripening approximately the third week in June, the same as for 'Rosalyne' (Khanizadeh et al., 2003).

The fruits are dark red, moderately glossy, and globose (Fig. 3) with some ridges. The fruit is large $(9 \mathrm{~g})$, whereas it is small $(1.5 \mathrm{~g})$ for 'Rosalyne', the calyx segments are outward to downward, the achenes are leveled with the surface, and the calyx is hard to hull. Ten percent to $20 \%$ of the flesh is medium red, whereas the balance is white. It is a bit soft like 'Rosalyne' but has an excellent, very aromatic flavor with medium sugar and acidity.
'Roseberry' strawberry is a wonderful variety for home gardeners who will get a continuous show of flowers all summer long in the garden accompanied by the production of very tasty fruits. It is especially recommended for use in hanging baskets because the stolons flower and fruit before rooting and they do not break under a high fruit load (Fig. 4).

\section{Availability}

'Roseberry' is a registered cultivar $(\mathrm{Ca}$ nadian Plant Breeders' Rights Certificate Number 1476) and the licenses for multiplication can be obtained from Agriculture and Agri-Food Canada, Horticulture Research and Development Center, 430 Gouin Boulevard, St-Jean-sur-Richelieu, QC, Canada, J3B 3E6.

\section{Literature Cited}

Hancock, J.F. 1999. Strawberries. CAB International, Wallingford, UK, p. 94.

Khanizadeh, S., J. Cousineau, M. Deschênes, A. Levasseur, and O. Carisse. 2003. 'Rosalyne' strawberry. Advances in Strawberry Research 21-22:17-18.

Royal Horticultural Society. 1995. Royal Horticultural Society colour chart. 3rd Ed. Royal Hort. Soc., London, UK. 